\title{
DIABETES DE HERENCIA MATERNA Y SORDERA
}

\section{MATERNALLY INHERITED DIABETES AND DEAFNESS}

\author{
SAMPEDRO A ${ }^{1}$, BARBÓN JJ ${ }^{1}$, ÁLVAREZ JA ${ }^{2}$, ANDRÉS MA ${ }^{3}$, BALDÓ C ${ }^{4}$
}

\section{RESUMEN}

Caso clínico: Se describe el seguimiento de un paciente diabético tipo 2 con una degeneración macular en patrón y sordera neurosensorial bilateral. En la electrofisiología mostraba un electrorretinograma (ERG) patrón anormal y un electrooculograma (EOG) disminuido.

Discusión: La presencia de diabetes de herencia materna y sordera neurosensorial, a los que suele sumarse una distrofia macular en patrón, constituyen el síndrome MIDD (Maternally Inherited Diabetes and Deafness), una rara enfermedad mitocondrial responsable de un $0,5 \%$ a $2,8 \%$ de los diabéticos.

Palabras clave: Diabetes, sordera, enfermedades mitocondriales, DNA mitocondrial, distrofia macular.

\section{INTRODUCCIÓN}

Las enfermedades mitocondriales comprenden un grupo de trastornos producidos por un fallo en el sistema de fosforilación oxidativa, la ruta final del metabolismo energético mitocondrial, con la consiguiente deficiencia en la biosíntesis de ATP (trifosfato de adenosina) ya que parte de los polipéptidos que

\begin{abstract}
Case report: We described the follow up of a patient with diabetes mellitus type 2 who had a macular pattern dystrophy and bilateral neurosensory hearing loss. Electrophysiological studies revealed abnormal pattern electroretinography and impaired electro-oculogram responses.

Discussion: Maternally Inherited Diabetes, neurosensory Deafness and generally macular pattern distrophy (MIDD syndrome), is a rare mitochondrial disease, responsible for approximately 0.5 to $2.8 \%$ of diabetes mellitus (Arch Soc Esp Oftalmol 2009; 84: 359-362).
\end{abstract}

Key words: Diabetes, deafness, mitochondrial diseases, mitochondrial DNA, macular dystrophy.

\footnotetext{
Recibido: 26/9/07. Aceptado: 3/7/09.

Hospital San Agustín. Avilés (Asturias). España.

1 Licenciado en Medicina. Servicio de Oftalmología.

2 Licenciado en Medicina. Servicio de Endocrinología.

3 Licenciado en Medicina. Servicio de Neurofisiología Clínica.

4 Licenciado en Medicina. Servicio de ORL.

Correspondencia:

A. Sampedro López

Servicio de Oftalmología. Hospital San Agustín

Camino de Heros, 4

33400 Avilés (Asturias)

España

E-mail: ansamlo@hotmail.com
}

componen este sistema están codificados en el DNA mitocondrial (mtDNA por sus siglas en inglés) (1).

La presencia de diabetes de herencia materna y sordera neurosensorial, a los que suele sumarse una distrofia macular en patrón, constituyen el síndrome MIDD, producido generalmente por una mutación del mtDNA en la posición A3243 y que es responsable de un $0,5 \%$ a $2,8 \%$ de los diabéticos $(2,3)$. 


\section{CASO CLÍNICO}

Paciente de 56 años que acudió a consulta en el año 1994 por presentar diabetes tipo 2 de 18 años de evolución, a tratamiento con insulina con regular control metabólico a la que se añadía una hipoacusia de nacimiento. En la exploración oftalmológica presentaba una agudeza visual de 1 en ambos ojos (AO) con corrección óptica, presión intraocular normal y un fondo de ojo sin retinopatía diabética pero con una alteración pigmentaria alrededor de la mácula. Al paciente se le realizó una angiografía con fluoresceína 1999 en la que se apreciaba una degeneración en patrón reticular en ambos polos posteriores e isquemia retiniana severa, por la que se realizó una fotocoagulación bilateral en la media perifería (figs. 1 y 2). A los cinco años desarrolló una retinopatía diabética proliferante en el ojo derecho (OD) con una hemorragia prerretiniana y se añadió fotocoagulación en la extrema periferia.

El paciente también fue sometido a cirugía de catarata en el ojo izquierdo (OI) en 2006 mediante facoemulsificación sin complicaciones. Actualmente presenta unas visiones de 0,5 en $\mathrm{AO}$, con una catarata cortical en el OD, seudofaquia en el OI y fondo de ojo con una retinopatía diabética fotocoagulada sin edemas maculares (figs. 3 y 4 ).

La exploración auditiva demostró una sordera neurosensorial bilateral y simétrica con una pérdida del $73 \%$ en oído derecho y del $63 \%$ en el izquierdo. En la electrofisiología apareció un Electrorretinograma Patrón (pERG) con ausencia de respuesta en
AO, un ERG Flash (fERG) de amplitud decrementada, un Electrooculograma (EOG) también disminuido y unos Potenciales Evocados Visuales normales.

El paciente, sin antecedentes familiares, fue estudiado genéticamente y las muestras de DNA procedentes de sangre periférica analizadas mediante secuenciación bidireccional confirmaron la presencia de la mutación en heteroplasmía c. 3243 A>G del tRNA(Leu) del mtDNA, compatible con una diabetes de herencia materna con sordera (MIDD).

\section{DISCUSIÓN}

La presencia de diabetes mellitus de herencia materna y sordera (MIDD) constituye un nuevo subtipo de diabetes asociado a la mutación A3243G del mtDNA que impide la entrada de leucina en la mitocondria (1). Esta mutación puntual es también una de las mutaciones asociadas al síndrome de encefalomiopatia mitocondrial con acidosis láctica y episodios de accidentes cerebrovasculares (MELAS), de la que el MIDD podría ser una forma de expresión parcial (1).

El mtDNA se transmite de forma casi exclusivamente materna: la madre transmite su genoma mitocondrial a toda su progenie debido al elevado número de mitocondrias que existen en el óvulo y a que las pocas que puede aportar el espermatozoide se eliminan por un proceso activo. La división celular puede originar líneas celulares con mitocondrias

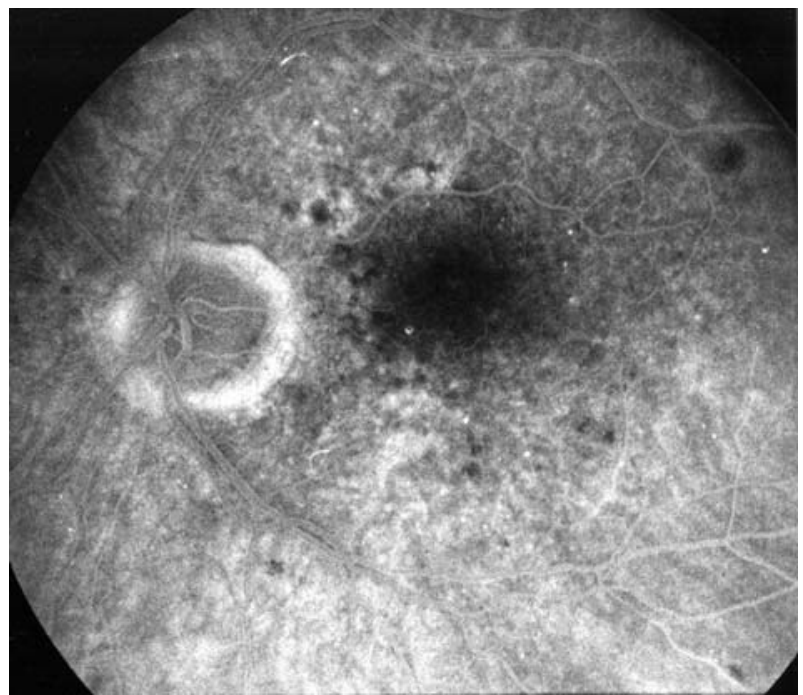

Figs. 1 y 2: Distrofia macular en patron en tiempos precoces del angiograma (incipiente). 

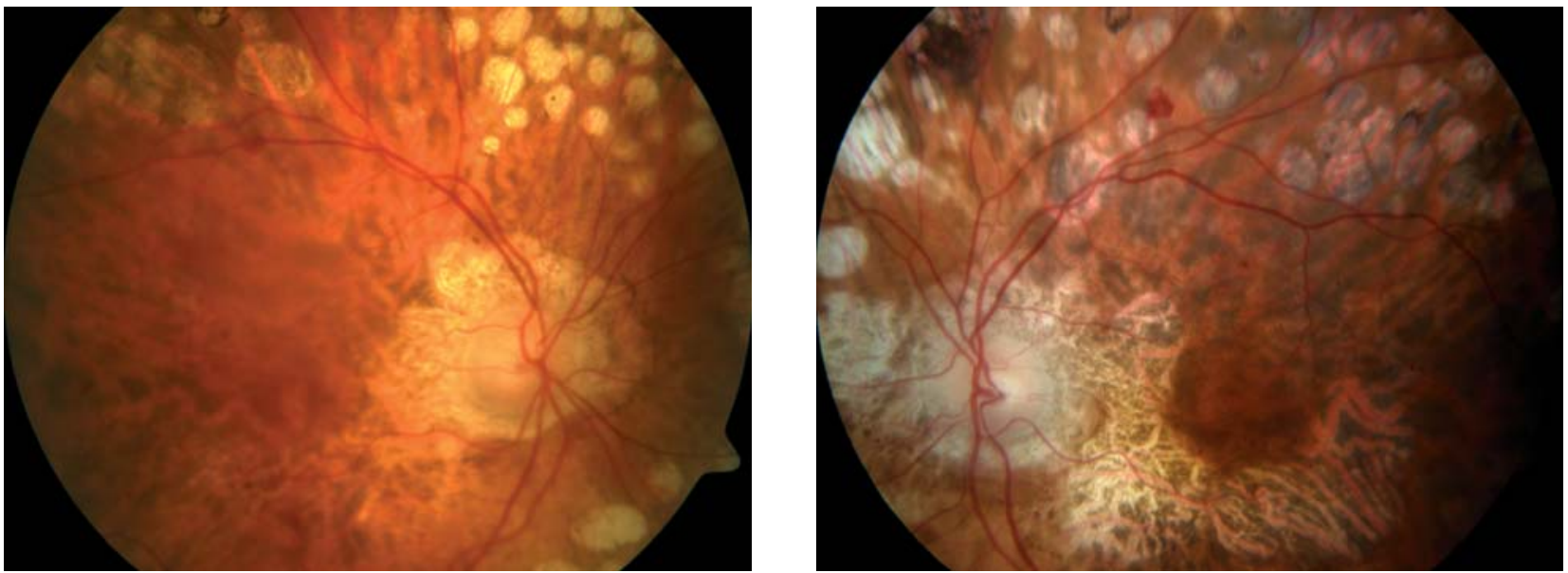

Figs. 3 y 4: Distrofia macular avanzada en el mismo paciente, con panfotocoagulación retiniana (10 años después).

normales y otras mutadas, a la mezcla de ambas se llama heteroplasmia. Cuando el DNA mutado sobrepasa un umbral determinado se manifiesta la enfermedad al quedar la producción de ATP por debajo de un mínimo necesario (1).

Clínicamente la diabetes aparece en adultos jóvenes (sobre los 40 años) y suele ser leve con tendencia evolutiva hacia la insulinopenia; los pacientes típicamente no son obesos y en un $80 \%$ hay antecedentes familiares de primer grado (2). La sordera, de tipo neurosensorial, aparece en un $98 \%$ y un $25 \%$ precisan ayudas auditivas. También puede asociar miocardiopatía, trastornos de la conducción cardiaca y síntomas neuro-psiquiátricos (2). Algunos pacientes presentan dolores musculares en extremidades inferiores con la deambulación prolongada, en estos casos la biopsia muscular muestra la presencia de fibras rojas rasgadas típica de las miopatías mitocondriales (2).

La alteración oftalmológica más frecuente es la presencia de una distrofia macular en patrón (en torno al 80\%), la mayoría de las veces asintomática. La visión suele estar conservada en un alto porcentaje de pacientes aunque pueden referir ceguera nocturna, fotofobia y déficit visual (2-4). Esta distrofia macular en el grado I presenta lesiones pigmentadas pequeñas localizadas en mácula, en el grado II se extienden alrededor de mácula y papila, y en el grado III, en estadios más avanzados, se observan parches de atrofia retiniana (2). Recientemente se ha descrito una menor prevalencia de retinopatía diabética y de hipertensión arterial en los diabéticos tipo MIDD frente a los diabéticos clási$\cos$, que por el contrario presentan mayores tasas de nefropatía (5). Son las alteraciones maculares características, visibles sobre todo en el angiograma de pacientes diabéticos, las que nos deben alertar sobre la existencia de un MIDD.

Las pruebas electrofisiológicas muestran disminución en la amplitud del pERG, que mide sobre todo la respuesta retiniana central, y alteraciones del EOG en la mitad de los casos (4). La coexistencia de un fERG decrementado en nuestro paciente, un registro difuso de la respuesta retiniana, estaría en relación a la fotocoagulación panretinal.

\section{BIBLIOGRAFÍA}

1. Solano A, Playán A, López-Pérez MJ, Montoya J. Enfermedades genéticas del ADN mitocondrial humano. Salud Pública Mex 2001; 43: 151-161.

2. Guillausseau PJ, Massin P, Dubois-LaForgue D, Timsit J, Virally $M$, Gin $H$, et al. Maternally inherited diabetes and deafness: a multicenter study. Ann Intern Med 2001; 134: 721-728.

3. Massin P, Virally-Monod M, Vialettes B, Paques M, Gin H, Porokhov B, et al. Prevalence of macular pattern dystrophy in maternally inherited diabetes and deafness. Ophthalmology 1999; 106: 1821-1827.

4. Smith PR, Bain SC, Good PA, Hattersley AT, Barnett AH, Gibson JM, et al. Pigmentary retinal dystrophy and the syndrome of maternally inherited diabetes and deafness caused by the mitochondrial DNA 3243 tRNALeu A to G mutation. Ophthalmology 1999; 106: 1101-1108.

5. Massin P, Dubois-Laforque D, Meas T, Lalois-Michelin M, Gin H, Bauduceau B, et al; GEDIAM (Mitochondrial Diabetes French Study Group). Retinal and renal complications in patients with a mutation of mitochondrial DNA of position 3243 (Maternally Inherited Diabetes and Deafness). A case-control study. Diabetologia 2008; 51: 16641670. 
